\title{
Analysis-based results on the delineation of prearrangement areas for marine renewable energy installations in the Western Black Sea Basin
}

\author{
Razvan Mateescu ${ }^{1,3, *}$, Elena Vlasceanu ${ }^{1,2}$ and Liliana Rusu ${ }^{3}$ \\ ${ }^{1}$ National Institute for Marine Research and Development “Grigore Antipa”, 300 Mamaia Blvd., RO-900581, Constanta, Romania \\ ${ }^{2}$ Constanta Maritime University, 104 Mircea cel Batran Street, Constanta, Romania \\ 3 'Dunarea de Jos' University of Galati, Department of Mechanical Engineering, 111 Domneasca Street, Galati, Romania
}

\begin{abstract}
The selection of optimum places for installations and suitable solutions for the use of marine renewable energy requires a complex approach as well as a longer period of time and a spatial scale hydrodynamic characterization, which time-limited and local studies are incapable to provide. To that end, the complex monitoring and modelling approach on the evolution of large-scale marine and coastal processes in response to both direct and indirect human intervention and to natural phenomena variability is an increasingly important issue in the Integrated Coastal Zone Management (ICZM) and MSP implementation, all over the world. The installation of wave/currents devices within coastal and marine areas involves the knowledge of the physical, economic and social impact of the continuous modification of the marine hydrodynamics, due to the new changes induced in the marine climate. The present work adequately takes into account the combined results of Marine Spatial Planning Directive applications within Western Black Sea Basin (WBSB). The MSP approach allows the selection of efficient areas for the installation of marine waves and currents devices converters (WECs), in relation with the potential environmental impact of adjacent MPAs, taking into account the induced strong variability of renewable devices/convertors on the coastal processes. Recommended areas for the installation of the abovementioned devices within highly energetic areas asked for a proper response in order to develop a detailed delineation targeting a sustainable coastal protection.
\end{abstract}

\section{Introduction}

The coastal zone is constantly changing in ways that impact every facet of our society. To that end, it is wellknown today that the coastal zones are among the most dynamic parts of the Earth. The systematic analysis, modelling/forecast and planning of these areas pose ongoing and very important challenges. This is important for the selection of the optimum solutions for socioeconomic activities dealing with the marine environment, especially for coastal protection against the implementation of the technical solutions, in relation with renewable energy [1-3], and, last but not least, with respect to the enhancement of ecosystem-based management.

For Romanian touristic littoral, the waves' regime was considered based on monitoring and numerical modelling, in relation with new protection measures for coastal navigation [4], and also, for new balneary developments, mainly for the delineations of suitable sites for thalassotherapy, close by high energetic coastal areas [5].

\footnotetext{
*Corresponding author: razvan_doru@yahoo.com
}

Also, the deployment of marine energy conversion equipment in key areas of waves/currents intensification is mainly approached by certain case studies on the implementation of various technologies as well as on its environmental impact.

The methodology that was used to collect, process and transmit the energy of the marine environment is under the attention of different regional stakeholders, represented by public authorities, marine planners and regulators, research institutes, university and specific developers. Since the Black Sea is a European marginal sea, where strong storms are distinctive, the investigations on such energy developments are extended in specific sites, taking in account its cumulative impacts on the marine/coastal ecosystems.

Due to the north-western Black Sea (NWBS) shore configuration and the general characteristics of the environment, Black Sea waves and circulation processes have a dynamic which is different than that in the case of the ocean [2,3]. Moreover, wind-generated waves in relation with inland water inflow and atmospheric phenomena induce specific hydrodynamic singularities in the coastal zones, noticed in the coastal system response modelling as well in case of marine energy usage. 
Consequently, certain necessities of existent vulnerabilities connected with regional network of Marine Protected Areas (MPAs) or different marine activities are considerate by MSP institutions for future larger scale installations at proper locations of the NW Black Sea Basin/Shore.

The implementation of the above-mentioned devices requires a multidisciplinary approach on the general trend and specific induced phenomena on the NWBS littoral/sea-land-interface, towards the understanding and mitigation of the impacted marine/coastal processes and certain specific components of marine life. The identification and quantification of the changes/impacts upon the Romanian coastal zone environment of the NW Black Sea is viewed in relation with the possible harmonization of different marine/coastal activities.

\section{Methodology}

The common methodology applied is connected to Geographic Information System (GIS) analysis and maritime spatial planning. Collecting information describing the plan area - indicators that are relevant for the processes present in the administrative units and data (texts and maps) from recent documents [6], useful for the plan preparation, marine and coastal context data relevant for the influences on the plan area [7], spatial planning documents and strategies relevant for the areas of technology implementation.

The ensuing result of this approach are the plan areas that are geographically delimited, significant spatial data and information on external influences on the plan area, together with provisions of recent spatial development plans and strategies pertaining to the marine energy convertors disposal [8-11], legislation and regulations relevant for the implementation of EU documents targeting maritime spatial planning [12].

The current situation analysis focused on the ecological and anthropic processes present in the marine area and the factors that affect their sustainable existence, in relation with the influences of energy devices [13, 14].

The following domains were subjects of analysis:

- Natural environment features/protection (physical, biological and valuable natural features, biodiversity and habitats, MPAs);

- Marine and coastal spatial features and resources (marine/coastal habitats, marine living and nonliving resources);

- General factors influencing the ecosystems (geographical and physical conditions of the marine and coastal areas, atmospheric/marine climate);

- Natural and anthropic harmful processes (quality status of the environmental constituents, natural and technological risks, pressures on marine environment);

- Built environment/Settlements network - coastal settlements affecting the marine space of possible implementations;

- Technical infrastructures networks (transport infrastructure, water management works, energy generation and transport, telecommunications, waste management);

- Marine and coastal activities/zoning - actual situation of marine habitats, marine areas for human uses (transport, fisheries, aquaculture, etc.), coastal areas (built-up areas, areas for agriculture, forests, protected areas, etc.), military training areas and facilities.

Analysis considered the NWBS supra-territorial context at regional level, such as transport corridors, development poles, and neighboring areas of ecosystems and the use of marine resources.

The spatial analysis of present (2017) in contrast to historic (1962) shoreline changes in relation with shore vulnerability index was realized in GIS environment.

\section{Results and discussions}

The results of this study provide an important support for the coastal planning/designing decisional process regarding the WQ/coastal ecosystem protection, erosion/accretion phenomena, the renewable energy/coastal facilities extensions.

The actual erosion state was emphasized on the base of shoreline retreat (figure 1) calculation in ArcGIS. The calculated results show that more than $75 \%$ of the total extent of Romanian shore is affected by erosion, therefore situation of the deployment of the renewable energy installations should be considerate as potential, if not compulsory, protection measures.

The key results provide an open perspective on the impact of the projects for marine energy, as well as on their relevance and direct application, jointly with a better knowledge of such results, potentially operational within wave and current climate in the NW Black Sea basin, including levels of impact on coastal dynamics. Certain realistic estimates on the installation of marine energy devices were identified at the mouths of the Danube River and the vicinity of the major marine obstacle/ports and natural capes/promontories of the NW BS Shore, in relation with environment ecological characteristics, Marine Protected Areas and marine/coastal activities and use [15]. Accordingly, facilitation, identification and selection of proper installation sites is possible, in keeping with the assessed historic shorelines and indicators of climate change vulnerability, and also in line with the relevant existing legislation and initiatives (Marine Strategy Framework Directive, Maritime Spatial Planning, and so on.

Environmental data analysis of existing conditions, existing economic sectors/uses and natural valuable areas was overlapped on a general layout highlighting the spatial representation of possible installation areas among identified marine activities and use of resources in the broader context of regional environmental conditions.

The main activities present on Romanian shore general layout (Figure 2) in relation with MSP approaches are shown together with MPAs (SCI network afferent to Constanta and Tulcea administrative units). The input of the RECZ areas and its specific considerations for Romanian maritime general layout was enquired by 
specific studies for maritime activities' harmonization and permit the completion of the MSP Directive implementation's processes [16].

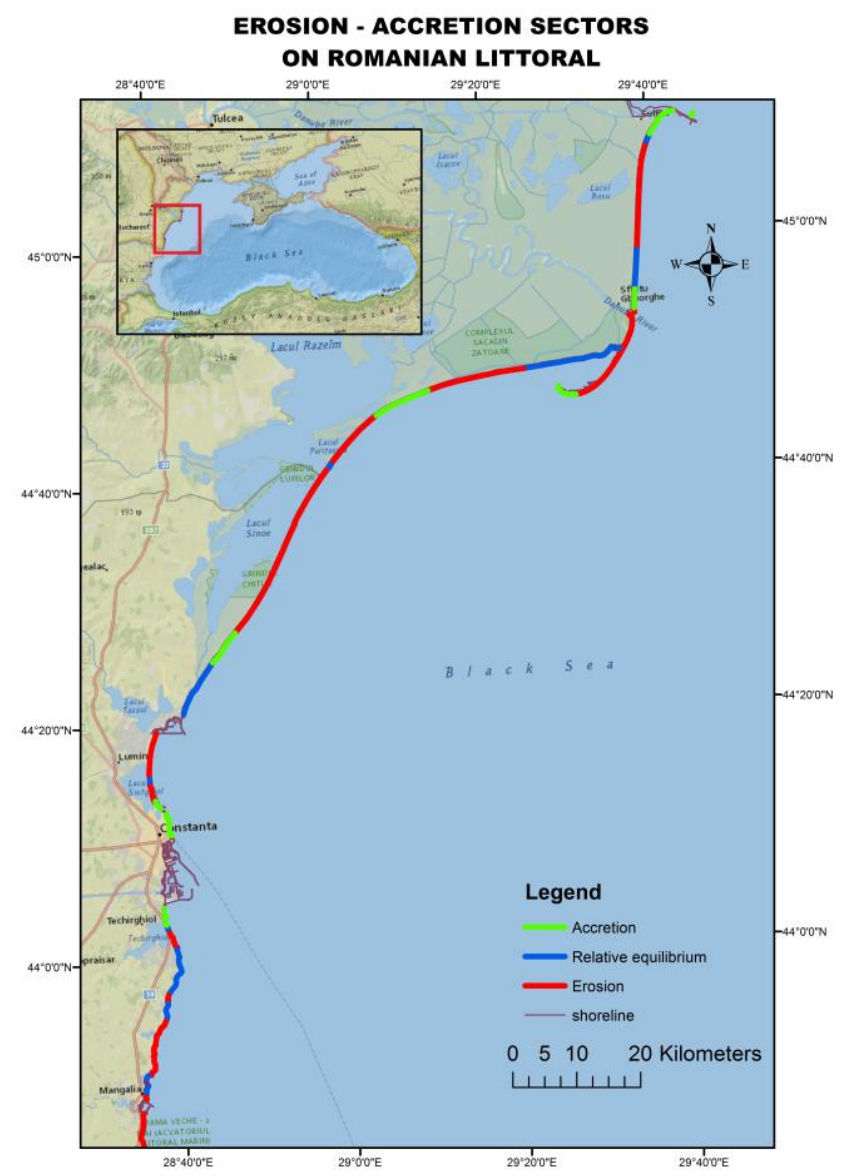

Figure 1. Coastal vulnerability sectors on Romanian littoral

\section{Conclusions}

The principles used in the present paper were the ecosystem - based approach (environment preservation, protection, improvement and resilience to climate change), sustainable development and growth in the maritime sector, and the harmonization the relevant maritime activities and levels of usage.

The present study is structured as a prequel to the prospective diagnosis approach and the extension of the implementation strategy of these technologies.

\section{Acknowledgments}

This work was supported by a grant of Romanian Ministry of Research and Innovation, CNCS UEFISCDI, project number PN-III-P4-ID-PCE-20160028, within PNCDI III.

\section{References}


15. L. Rusu, D. Butunoiu, E. Rusu, J. Environ. Prot. Ecol. 15(2), 445-454 (2014)

16. E. Vlasceanu, D. Niculescu, I. Omer, E. Rusu, A. Ivan, SGEM 3(2), 675-682 (2015) 